\title{
Passive Acoustics as a Tool in Fisheries Science
}

\author{
JosePH J. LUCZKOVICH* \\ Department of Biology, Institute for Coastal and Marine Resources, East Carolina University, \\ Greenville, North Carolina 27858, USA
}

DAVID A. MANN

College of Marine Science, University of South Florida, 140 Seventh Avenue South, St. Petersburg, Florida 33701, USA

\author{
Rodney A. Rountree \\ Marine Ecology and Technology Applications, Inc., 23 Joshua Lane, Waquoit, Massachusetts 02536, USA
}

\begin{abstract}
Many fishery biologists that are interested in documenting fish habitat and following the movements and behavior of fishes use acoustic tags. Because over 700 fish species naturally produce lowfrequency, species-specific sounds, these can be used as natural acoustic tags. Passive acoustic approaches (monitoring sound-producing fishes with hydrophones) show great promise for gathering data in a noninvasive and continuous manner. In this special section, authors review past studies and contribute new findings based on the concept of passive acoustics, in which the sounds produced by fish are used to identify the species present and quantify their relative abundance. Fish have long been known to produce lowfrequency sounds, especially members of the families Sciaenidae, Gadidae, Ictaluridae, Cyprinidae, Batrachoididae, Haemulidae, Lutjanidae, and Serranidae. Passive acoustic methods include the use of lowfrequency hydrophones, digital recorders, autonomous recording sonobuoys and data loggers, and towed hydrophone arrays to record fish sounds. The sounds of fishes that have been recorded so far have been described in monographs, scientific papers, and online digital libraries; in most cases, the recordings are species specific and can be used to identify fish. Work is progressing in using the passive acoustic approach along with traditional fisheries sampling methods (net and active acoustic surveys) to identify habitat use, spawning areas, and relative abundances. The authors in this special section present new passive acousticsderived data on sciaenids, batrachoidids, and ictalurids. They outline the methods currently being used and discuss their limitations, provide examples where passive acoustics has been employed successfully, warn of pitfalls in interpreting acoustic data, and lay the groundwork for future studies.
\end{abstract}

Many fishery biologists are interested in following the movements and behavior of fishes by use of active ultrasonic acoustic tagging, in which fishes are rigged with an active acoustic tag that transmits its location to hydrophone receivers. The emerging field of passive acoustic methodology in fisheries surveys takes advantage of the fact that many species of fish naturally produce sounds and therefore possess natural acoustic tags. Passive acoustics utilizes low-frequency $(<10 \mathrm{kHz})$ hydrophones to detect and monitor natural sound production by fishes, which is typically associated with feeding, aggressive encounters, courtship, or spawning behavior. Passive acoustics has a long history in fish biology, but it has only recently been applied to fisheries and their management (Rountree et al. 2006). Because most of these sounds are species specific, one can use a hydrophone to listen

\footnotetext{
* Corresponding author: luczkovichj@ecu.edu
}

Received November 19, 2006; accepted September 10, 2007 Published online April 3, 2008 for sounds associated with specific behaviors. The temporal and spatial patterns of behaviors, such as spawning, can then be inferred simply by recording and analyzing the sounds using signal processing techniques. The use of passive acoustics as a modern tool for fishery investigations in a digital age suggests some interesting possibilities and questions.

How many fishes are sound producers (i.e., already acoustically tagged)? There are more than 700 species known to produce sounds from at least 30 families (Fish and Mowbray 1970; Kaatz 2002; Johnston and Phillips 2003; Johnston and Vives 2003; Rountree et al. 2006), and many more soniferous fishes have yet to be recorded. Are these species harvested in commercial and recreational fisheries? Although the diversity of soniferous fishes is poorly understood, a partial list of sound producers that are caught recreationally or sold commercially would include members of Sciaenidae (Mok and Gilmore 1983; Johnson and Funicelli 1991; Saucier et al. 1992; Saucier and Baltz 1993; Luczkovich et al. 1999; Gilmore 2002; Roumillat and Brouwer 2004), Gadidae (Brawn 1961c; Hawkins et al. 1967; 
Hawkins and Rasmussen 1978; Hawkins and Amorim 2000; Finstad and Nordeide 2004; Rowe and Hutchings 2006), Clupeidae (Wahlberg and Westerberg 2002), Salmonidae (Neproshin 1972), Ictaluridae (Fine et al. 1997), Carangidae (Fish and Mowbray 1970), Centrarchidae (Gerald 1971), Cyprinidae (Johnston and Vives 2003), Acipenseridae (Johnston and Phillips 2003), Anguillidae (Fish and Mowbray 1970), Ophidiidae (Perez et al. 2003; Fine et al. 2007), Batrachoididae (Fine 1978; Collette and Klein-MacPhee 2003:264; Amorim et al. 2006), Lutjanidae (Fish and Mowbray 1970), Haemulidae (Burkenroad 1931; Fish and Mowbray 1970), Gobiidae (Adams et al. 2001; Lugli et al. 2003), and Serranidae (Fish and Mowbray 1970; Lobel 1992, 2002). The reader is referred to Kaatz (2002) and Rountree et al. (2006) for a detailed discussion of the taxonomic distribution of sound production in fishes.

Can sound production be used for tracking movement and behaviors of sound-producing fishes (i.e., are these sounds acting as natural, self-recharging acoustic tags)? Although this is an application of passive acoustic monitoring that is still being developed, sounds are produced routinely and for long periods of time by these fishes, allowing for seasonal and diurnal tracking of large shoals. Luczkovich et al. (1999) used hydrophones to track the migration and seasonal spawning patterns of weakfish Cynoscion regalis in Pamlico Sound, North Carolina. McCauley and Cato (2000) described the daily summertime calling cycle of different fish species by means of a fixed listening station on the Great Barrier Reef in Australia; peak sound levels were measured at night, but at least some fishes made sounds during each hour of the day. D'Spain and Batchelor (2006) were able to track the vertical migration of sciaenid fishes by using a large, vertical hydrophone array in the Southern California Bight. Energy for sound production comes from the fish themselves using their drumming muscles or stridulatory mechanisms, and these muscles are fascinating examples of vertebrate evolution. The sonic muscles are among the fastest-contracting muscles (e.g., those of oyster toadfish Opsanus tau can contract at $400 \mathrm{~Hz}$; Fine et al. 2001). In addition, some fish (e.g., weakfish) have long-duration calling activity and have been recorded to produce sounds continually between 1200 and 0400 hours (Connaughton and Taylor 1995). Plainfin midshipmen Porichthys notatus produce individual calls that last for many hours (Ibara et al. 1983).

At what distance can these sounds be detected? The range over which a fish sound can be detected varies with sound source levels and background sound levels. Propagation distances measured for a single silver perch Bairdiella chrysoura were between 2 and $316 \mathrm{~m}$ in the presence of a background sound level of 110 $125 \mathrm{~dB}$ relative to (re) a reference effective pressure of $1 \mu \mathrm{Pa}$, assuming cylindrical spreading and a source sound level of $128-135 \mathrm{~dB}$ re $1 \mu \mathrm{Pa}$ (Sprague and Luczkovich 2004). Luczkovich et al. (1999) concluded that large aggregations of spawning weakfish and silver perch in Pamlico Sound could be detected at least $1 \mathrm{~km}$ from the source based on the recorded sound level of $147 \mathrm{~dB}$ re $1 \mu \mathrm{Pa}$. D'Spain and Batchelor (2006) estimated that a chorus of fishes and invertebrates from a popular fishing spot off California was detectable at 2 $\mathrm{km}$ using a 131-element hydrophone array and beamforming signal processing techniques, although individual fish calls could not be distinguished from the background sound. McCauley and Cato (2000) estimated that large shoals of largescale grunters Terapon theraps (family Terapontidae) could be heard at a distance of 5-8 km from the center of the shoal on the Great Barrier Reef.

What if almost every individual of a population or a particular life stage had natural acoustic tags that provided information on fish size, species, and spawning location? This is generally the case but requires additional study, as it can vary by species (Fish and Mowbray 1970; Rountree et al. 2006), or may be restricted to certain life stages or sexes or to the reproductive period (Hill et al. 1987; Mann and Lobel 1995b; Connaughton et al. 1997, 2000). The details of the answers to some of these questions, especially this last one, are contained within the papers that follow.

In this paper, we introduce a group of papers that grew out of a passive acoustics symposium at the 2003 Annual Meeting of the American Fisheries Society in Quebec City, Canada. Individual papers are described in a separate section below. This special section is intended to be a selection of papers that highlight new studies of fishery species (mostly sciaenids) and a guide to those who are interested in using passive acoustics to monitor behavior and spawning of fishes.

It is good to remember while reviewing these studies that not all fishes produce sounds. Also, in most species, the sounds are not produced continuously but rather are produced more commonly at night and during periods of specific behavioral activities, such as courtship, aggression, disturbance, and feeding. Some species will not produce sound at all life stages or in both sexes, and others will. These challenges make interpretation of the results more difficult than those derived from ultrasonic tags attached to a small number of fish of known species, size, and sex that have been released in a given location and then tracked spatially. It is precisely this challenge that we tackle in this special section, hoping to stimulate further research in 
passive acoustics in fisheries. We join a growing group of physicists and biologists who are researching this topic. For example, passive acoustic surveys as a census tool are now a part of the national effort to census marine life and fisheries species (Van Parijs and Southall 2007; see also NOAA 2007) and are being explored as a potential tool for monitoring remote areas of the sea (ACT 2007).

\section{Historical Studies of Sound Production by Fishes}

There is a long history in the study of fish sound production. Indigenous peoples and Chinese fishers have used the sounds produced by spawning fish to "hunt" for fishing locations (Sadovy and Chung 2003). Aristotle was the first to describe the sounds of fishes (Thompson 1910). One of the first accounts of fish sound production in modern times came from Charles Darwin's correspondence. Fritz Mueller communicated to Darwin about the sound production of fishes in Brazil (Mueller 1867): "In this connection I would like to add that there is a fish in the sea by Santa Catharina which produces very melodious sounds which may also serve to attract the opposite sex. The sounds are like the ringing of distant church bells. I only ever heard them on quiet evenings when these maritime musicians swam by a rock close to the coast, but I never saw the fish." It is worth noting that this fish has not been identified, even today. This is an example of how fish sounds are often heard by observers on land and how much work is still left to do in this area.

In a pioneering study of weakfish, Tower (1908) determined that the mechanism of sound production in sciaenids was the sonic muscles surrounding the swim bladder. Today, this remains one of the best studies of the mechanism of sound production in any fish. Burkenroad (1931) studied sound production in Louisiana fishes, noting the disturbance calls of each specimen and obtaining data from sound-producing toadfishes, midshipmen, seahorses, catfishes, spadefishes, and grunts in otter trawls, seines, and hook-andline catches while working with commercial fishers. He did not have any hydrophones or sound-recording equipment, so his notes on disturbance calls in air are all that we have of this first soniferous-fish and fisheries survey. In the period around World War II, great strides were made in hydrophone technology in the USA and Britain, as the need to track submarines created intense interest in listening to the sounds of the sea. To the surprise of some early naval researchers, the sounds of the sea from "biological sources" were so loud that they often obscured vessel noise, making it difficult to track a vessel (Dobrin 1947). Interestingly, this U.S. Navy hydrophone study was quite accurate and Dobrin (1947) correctly interpreted that sciaenids were most likely to have produced the sounds. For example, the frequency of biological sound detected by Dobrin from hydrophone recordings made at Fort Macon, North Carolina, was $600 \mathrm{~Hz}$, from which he correctly noted that "... the source is very likely to be croakers" (Dobrin 1947:20); later, it was discovered that Atlantic croakers Micropogonias undulatus recorded in captivity have a dominant frequency of 300$600 \mathrm{~Hz}$, which varies inversely with fish size (Fish and Mowbray 1970). Dobrin (1947) also noted that the sound frequency decreased during the season, which he attributed to fish growth; larger fishes have larger swim bladders, thus producing lower dominant frequencies.

It was during this time that the U.S. Navy funded the work of Marie Poland Fish and William Mowbray, who catalogued many of the soniferous fishes in the Atlantic coastal waters of the USA (Fish et al. 1952; Fish and Mowbray 1970). The work of these two biologists, along with that of William Tavolga on gobies and blennies (Tavolga 1958, 1960), Art Myrberg on damselfishes and reef fishes (Myrberg 1980, 1981; Myrberg et al. 1986, 1993), Howard Winn on toadfishes (Gray and Winn 1961; Winn 1964, 1967) and squirrelfishes (Winn et al. 1964), Paul Perkins (Perkins 2001; who also worked with Winn, Fish, and Mowbray), and William Cummings on reef fishes and sciaenids (Cummings et al. 1964; Fish and Cummings 1972), advanced the field during the 1960s and 1970s. Many advances occurred because of a special installation of hydrophones and an underwater television camera off the Lerner Marine Laboratory in Bimini, Bahamas, which allowed these researchers to identify soniferous fish species and study additional mechanisms and behaviors associated with sound production, as described in a special symposium held there in 1963 (Tavolga 1964, 1967). One major advance during the 1960s was the discovery that Atlantic cod Gadus morhua and haddock Melanogrammus aeglefinus held in captivity produce sounds associated with both aggression and reproduction (Brawn 1961a, 1961b, 1961c; Hawkins et al. 1967). Based on these laboratory observations, Anthony Hawkins and his colleagues expanded the study of sound production to record haddock and Atlantic cod in natural spawning areas (Hawkins and Rasmussen 1978; Hawkins and Amorim 2000; Hawkins et al. 2002). The use of passive acoustics to monitor the spawning stock status of these gadid fishes is an ongoing focus of research for this group and others (Nordeide and Folstad 2000; Bremner et al. 2002; Hawkins et al. 2002; Finstad and Nordeide 2004; Rowe and Hutchings 2004; for a summary, see Hawkins 1986 and Rountree et al. 2006).

One of the most extraordinary early passive acoustic studies was that carried out by Thomas Bright as part 
of the Tektite Project (Bright 1972). In 1969, scientists living in the underwater habitat located in $15 \mathrm{~m}$ of water within Lameshur Bay, St. John, U.S. Virgin Islands, collected extensive underwater acoustic and video observations on fish behavior. They reported on the sounds and behaviors of a number of important fishes, including groupers (Serranidae). Notably, they included examples of underwater sounds on a vinyl record published with the Tektite Report (Collette and Earle 1972). The study provides detailed spectrographic analysis and data on correlations between acoustic activity and specific behavior patterns and remains one of the most comprehensive studies of its type to date.

Some of the most significant work on fish sound production occurred in the 1980s through the present because of studies conducted by Michael Fine and his students on sound production by oyster toadfish (Fine et al. 1977a, 1977b, 2001; Fine 1978; Fine and Lenhardt 1983; Fine and Pennypacker 1986; Barimo and Fine 1998; Thorson and Fine 2002), sciaenids (Connaughton et al. 1997, 2000, 2002), and channel catfish Ictalurus punctatus (Fine et al. 1997). Fine and colleagues have shown conclusively that toadfish and weakfish sound production varies with temperature (Fine 1978; Connaughton et al. 2000, 2002), and toadfishes have some of the fastest vertebrate muscle contractions known (Rome et al. 1996; Fine et al. 2001). They have demonstrated that sounds of the toadfish do not propagate more than several meters (Fine and Lenhardt 1983) but do so in a directional pattern that can be detected by females (Barimo and Fine 1998). These sounds are clearly reproductive advertisement calls, and hormonal conditions cause the development and growth of the swim bladder in toadfish (Fine and Pennypacker 1986; Fine 1997). Martin Connaughton has worked extensively with Fine on weakfish (Connaughton et al. 1997, 2000, 2002) and continues to contribute significantly in the field of fish sound production, demonstrating that testosterone implants cause development of drumming muscles in weakfish (Connaughton and Taylor 1995). Recently, Fine et al. (in press) described a novel new mechanism of sound production in ophidiids that allows for relatively high-frequency sound production.

Another notable scientist in the field of passive acoustics includes Phil Lobel, who has studied sound production in parrotfishes (Scaridae), damselfishes (Pomacentridae), and hamlets Alphestes spp. (Serranidae) on coral reefs. Sounds produced by parrotfishes and hamlets are associated with reproduction and gamete release (Lobel 1992). Lobel and David Mann showed that male domino damselfish Dascyllus albisella produced a distinctive sound while aggressively interacting with other males and during spawning visits by females (Lobel and Mann 1995). They developed an early computerized passive acoustic monitoring system to document the sounds, modeled propagation distances, and obtained real-time records of spawning events (Mann and Lobel 1995a, 1995b, 1997, 1998). Lobel (2001) developed an underwater video recorder system used in conjunction with a closed-circuit rebreather to obtain simultaneous video and audio of these reef fishes and has since constructed a list of fishes that make spawning sounds, including members of Ostraciidae, Pomacentridae, Serranidae, and Scaridae (Lobel 2002).

Important research linking sound production and reproduction of commercially important species began in the 1980s with drum fishes in the shallow estuarine systems of Florida. Michael Mok and Grant Gilmore (Mok and Gilmore 1983) used a continuously recording hydrophone and mobile hydrophone transect surveys combined with ichthyoplankton collections to demonstrate that sound production by males was related to egg production by females in black drum Pogonias cromis, silver perch, and spotted seatrout $C$. nebulosus. Gilmore (2003) continued to study spotted seatrout in great detail, obtaining the first captive recordings of this species, providing an excellent review of sound production mechanisms, costs, and spectral properties and the spatial and temporal distribution of sound production sites and spawning habitats. Donald Baltz, William Roumillat, and Michael Saucier have extended Mok and Gilmore's (1983) approach and have also identified spotted seatrout spawning areas in South Carolina by using passive acoustics (Saucier et al. 1992; Saucier and Baltz 1993; Roumillat and Brouwer 2004). More recently, Joseph Luczkovich and Mark Sprague (Luczkovich et al. 1999, 2008, this issue; Sprague and Luczkovich 2004) have developed much of their research in North Carolina based on the groundwork laid down by Mok and Gilmore.

Many of the pre-2000 studies have been conducted using analog recording equipment and dedicated sonograph machines for analysis and relying on magnetic tape recordings from earlier studies to identify the species on their recordings. The quality of these magnetic sound recordings is deteriorating, and the Fish and Mowbray archive was nearly lost to science (see Rountree et al. [2002, 2006] for a discussion of the data rescue effort). More recently, people have been sharing digital audio recordings and using computer spectral analysis programs to process the data. The cost of recording and storing the sounds of the fishes in the sea is less than ever before, but the recordings are just as ephemeral should a hard drive crash. The MacCaulay Library of Natural Sounds at 
Cornell University (Cornell Ornithology Laboratory 2007) is serving as the primary repository of these historical recordings and is expected to develop into a National Reference Collection as newer materials are added.

\section{Passive Acoustics Special Section}

The papers in this special section span a range of topics from descriptive studies of in situ recordings, some of yet-unidentified origin, to studies of captive fishes and field recordings. Five of the papers focus on sciaenids and the others concern catfishes and toadfishes, all of which are targets of fisheries around the world. Two symposium papers describing Atlantic cod sound production in association with spawning, one by Jarle Nordeide of Bodo Regional University in Norway and one by Sherry Lynn Rowe of Dalhousie University, have since been published elsewhere (Finstad and Nordeide 2004; Rowe and Hutchings 2004).

Scott Aalbers and Mark Drawbridge present the first description of sounds from white seabass Atractoscion nobilis (Aalbers and Drawbridge 2008, this issue). They used a unique spawning pen in the open ocean near Catalina Island, California, to observe fish in a near-natural environment that was semicontrolled to permit video and audio recording of individuals of known size and sex. Using simultaneous video and sound recordings, they demonstrated that sound production was associated with spawning but that males only produce the sounds immediately prior to spawning. Egg collections made at regular intervals from the pens were correlated in time with the sound production, suggesting that the monitoring of sound production can be used as a surrogate for egg production; this will be important for converting passive acoustic surveys to fish adult numbers in the development of egg production models. They observed a special rapid type of call, termed a "drum roll," which appears to be associated with spawning events. Their observations on behavior and sound production together set a new standard for others to follow, as it is rare to get such good visual and auditory sound truthing in a nearly natural system.

Scott Holt presents the first application of a towed hydrophone array in fisheries in a study of the distribution of spawning red drum Sciaenops ocellatus along the coast of Texas (Holt 2008, this issue). This method holds great promise for spawning habitat surveys, because mobile passive acoustic studies can now be conducted over a wide portion of the coastline and areas where fish might be spawning can be noted based on the peak sound pressure levels that occur as the array is towed past the spawning sites. However, a limitation is that data obtained from a towed hydrophone array will be unable to separate temporal and spatial differences, given that fishes do not produce sounds equally at all times of the night. Interestingly, Holt's results suggest that (1) red drum spawning and sound production occur in offshore shelf habitats, (2) males are widely spaced rather than tightly aggregated, and (3) estuaries are not used during spawning. These kinds of observations have been lacking in habitat use models of red drum, and they have obvious management implications. This adult distribution is different from that of red drum spawning along the U.S. Atlantic coast, which appears to be estuarine based as determined using passive acoustics (Johnson and Funicelli 1991; Lowerre-Barbieri et al. 2008, this issue; Luczkovich et al. 2008, this issue). Further data are needed to compare the Atlantic coast and Gulf of Mexico red drum populations and their spawning behaviors.

Susan Lowerre-Barbieri, Luiz Barbieri, J. R. Flanders, Arnold Woodward, Chip Cotton, and Kathryn Knowlton, also working with red drum, determined the types of sound associated with spawning in a captive group and then used that information along with passive acoustic recordings from field sites to characterize the location and timing of red drum spawning in coastal Georgia estuaries (Lowerre-Barbieri et al. 2008, this issue). These authors did not detect any sound production by red drum on the continental shelf outside the inlets, a finding that differs from the distribution described by Holt (2008, this issue) for red drum in the Gulf of Mexico. The paper by Lowerre-Barbieri et al. (2008, this issue) is significant because it clearly demonstrates that drumming rate changes with spawning activity as recorded in a tank and that the unique drum rolls (similar to those observed in white seabass by Aalbers and Drawbridge 2008, this issue) produced by males coincide with egg production by females in both the laboratory and field sites. The behavioral significance of such calls was unknown in this species prior to this study and is poorly studied in most species (except haddock: Hawkins and Amorim 2000). This study sheds light on how some qualitatively distinct sound production precedes spawning and can be used to target the precise spawning sites and times in red drum.

Joseph Luczkovich, Chris Pullinger, Stephen Johnson and Mark Sprague mapped the spawning habitat of weakfish, silver perch, spotted seatrout, and red drum in Pamlico Sound using sonobuoy-type autonomous recorders (Luczkovich et al. 2008, this issue). They compared variation of the sound production of these fishes using a qualitative drumming index with variation in water quality and habitat parameters, 
especially depth, temperature, salinity, and dissolved oxygen. They demonstrate the usefulness of having simultaneous recording devices operating over a wide spatial area and deployed in a regular time frame to allow spatial and temporal mapping of spawning habitat use. This approach may have advantages over a towed array in certain situations, because the samples are taken over a wide area simultaneously. Clear differences in spawn timing and spawning location among the four species were discovered, suggesting that these species subdivide the available environment temporally and spatially during reproductive activities. They detected red drum spawning in the estuary (as was also observed by Lowerre-Barbieri et al. 2008, this issue), but they did not sample offshore beyond the inlets. These authors point the way towards the future development of coastal observatories for monitoring fish spawning events by relying on the new generation of digital passive acoustic recorders that are currently being developed.

James Locascio and Mann used such digital passive acoustic recorders to study sound production by silver perch and sand seatrout $C$. arenarius over long temporal scales in Charlotte Harbor, a Florida estuary (Locascio and Mann 2008, this issue). They demonstrated a clear nocturnal pattern of sound production by these species. Their unique recording device (the longterm acoustic recording system) shows great promise for automating the process of recording low-frequency fish sounds in a regular sampling schedule over a period of days to months and recording the files to digital media. This device will greatly facilitate the study of fish habitat use by passive acoustic surveys in the future.

Katie Anderson, Rodney Rountree, and Francis Juanes conducted the first passive acoustic survey of a freshwater system in which they point out the paucity of data on freshwater fish sound production and call for research to catalog soniferous fishes in other freshwater systems (Anderson et al. 2008, this issue). They sampled in the Hudson River from tidal freshwater $(<0.5 \%)$ habitats within the Tivoli Bay National Estuarine Research Reserve (located $153 \mathrm{~km}$ from the river mouth) and from a mesohaline (5-18\%) site located on the docks of New York City ( $3 \mathrm{~km}$ from the river mouth). They recorded sounds from oyster toadfish and striped cusk-eels Ophidion marginatum at New York City and brown bullheads Ameiurus nebulosus and channel catfish at Tivoli Bay. Perhaps the most striking finding was the large number of unknown fish sounds that were recorded at the freshwater site.

Fine and Robert Thorson show how passive acoustics can be used to study individual interactions among Gulf toadfish Opsanus beta in Florida, a species that produces alternating calls (Fine and Thorson 2008, this issue). Fine and Thorson term this acoustic "tagging" (not to be confused with the application of active ultrasonic tags to fish) in which one male Gulf toadfish attempts to call immediately after another nearby male has called, a type of acoustic competition. This acoustic tagging work has implications for fishery biologists interested in sound production, because individual Gulf toadfish can be identified in these recordings, demonstrating that a natural, individual fish tag is possible.

Finally, Damon Gannon critically reviews the fish passive acoustics literature and suggests how the field should move forward (Gannon 2008, this issue). In this review, he notes that most of the papers on fish sound production and detection have been published in journals not normally read by fisheries biologists, such as the Journal of the Acoustical Society of America and Bioacoustics. He encourages fishery biologists to read those journals but also to consider undertaking research using passive acoustic methods, and he calls for fishery journals to publish more bioacoustic studies.

Taken together, these papers show several approaches for making passive acoustic recordings in the field. It is important to remember that these papers include only a few of the many species of soniferous fishes. Although we have known for quite a long time that fish make sounds, the use of passive acoustics as applied to fisheries is a young science. These studies show the great potential for the use of passive acoustic approaches to study fish behavior and spawning (Rountree et al. 2006). As more studies in passive acoustics are completed, we expect this approach to be used in a complementary way with active acoustic studies (Horne 2000) and traditional net-based surveys. Ultimately, we anticipate that passive acoustic monitoring of fishes on ocean observing platforms will be implemented and then combined with these traditional methods to produce spawning stock estimates. The goal of this special section is to stimulate research in these areas.

\section{References}

Aalbers, S. A., and M. A. Drawbridge. 2008. White seabass spawning behavior and sound production. Transactions of the American Fisheries Society 137:542-550.

Adams, C. M., S. L. Larkin, and D. J. Lee. 2001. Volume and value of marine ornamentals collected in Florida, 19901998. Aquarium Sciences and Conservation 3:25-36.

ACT (Alliance for Coastal Technologies). 2007. Underwater passive acoustic monitoring for remote regions: a workshop of research scientists, technology developers, and resource managers. Hawaii Institute of Marine Biology, Coconut Island, February 7-9, 2007. Alliance 
for Coastal Technologies Reference Number ACT-07-02 Available: http://www.act-us.info.

Amorim, M. C. P., R. O. Vasconcelos, J. F. Marques, and F. Almada. 2006. Seasonal variation of sound production in the Lusitanian toadfish (Halobatrachus didactylus). Journal of Fish Biology 69:1892-1899.

Anderson, K. A., R. A. Rountree, and F. Juanes. 2008. Soniferous fishes in the Hudson River. Transactions of the American Fisheries Society 137:616-626.

Barimo, J. F., and M. L. Fine. 1998. Relationship of swimbladder shape to the directionality pattern of underwater sound in the oyster toadfish. Canadian Journal of Zoology 76:134-143.

Brawn, V. M. 1961a. Aggressive behaviour in the cod (Gadus callarias L.). Behaviour 18:107-147.

Brawn, V. M. 1961b. Reproductive behaviour of the cod (Gadus callarias L). Behaviour 18:177-198.

Brawn, V. M. 1961c. Sound production by the cod (Gadus callarias L.). Behaviour 18:239-245.

Bremner, A. A., E. A. Tripple, and J. M. Terhune. 2002. Sound production by adult haddock, Melanogrammus aeglefinus, in isolation, pairs and trios. Environmental Biology of Fishes 65:359-362.

Bright, T. J. 1972. Bio-acoustic studies on marine organisms. Pages $45-70$ in B. B. Collette and S. A. Earle, editors. Results of the Tektite Program: ecology of coral-reef fishes. Los Angeles County Natural History Museum Science Bulletin, Volume 14

Burkenroad, M. D. 1931. Notes on the sound-producing marine fishes of Louisiana. Copeia 1931:20-28.

Collette, B. B., and S. A. Earle, editors. 1972. Results of the Tektite Program: ecology of coral-reef fishes. Los Angeles County Natural History Museum Science Bulletin, Volume 14.

Collette, B. B., and G. Klein-MacPhee, editors. 2003. Bigelow and Schroeder's fishes of the Gulf of Maine, 3rd edition. Smithsonian Institution, Washington, D.C.

Connaughton, M., and M. Taylor. 1995. Seasonal and daily cycles in sound production associated with spawning in the weakfish, Cynoscion regalis. Environmental Biology of Fishes 42(3):233-240.

Connaughton, M. A., M. L. Fine, and M. H. Taylor. 1997. The effects of seasonal hypertrophy and atrophy on fiber morphology, metabolic substrate concentration and sound characteristics of the weakfish sonic muscle. Journal of Experimental Biology 200:2449-2457.

Connaughton, M. A., M. L. Fine, and M. H. Taylor. 2002. Weakfish sonic muscle: influence of size, temperature, and season. Journal of Experimental Biology 205:21832188.

Connaughton, M. A., M. H. Taylor, and M. L. Fine. 2000. Effects of fish size and temperature on weakfish disturbance calls: implications for the mechanism of sound generation. Journal of Experimental Biology 203(9):1503-1512.

Cornell Ornithology Laboratory. 2007. Macaulay library of natural sounds. Cornell Ornithology Laboratory, Ithaca, New York. Available: http://www.birds.cornell.edu/ macaulaylibrary.

Cummings, W. C., D. D. Brahy, and W. F. Herrnkind. 1964. The occurrence of underwater sounds of biological origin off the west coast of Bimini, Bahamas. Pages 27-43 in
W. N. Tavolga, editor. Marine bio-acoustics. Pergamon Press, New York.

D'Spain, G. L., and H. H. Batchelor. 2006. Observations of biological choruses in the Southern California bight: a chorus at midfrequencies. Journal of the Acoustical Society of America 120:1942-1955.

Dobrin, M. B. 1947. Measurements of underwater noise produced by marine life. Science 105(2714):19-23.

Fine, M. L. 1978. Seasonal and geographic variation of the mating call of the oyster toadfish, Opsanus tau. Oecologia 36:45-57.

Fine, M. L. 1997. Endocrinology of sound production in fishes. Marine and Freshwater Behavior and Physiology 29:23-45.

Fine, M. L., J. P. Friel, D. McElroy, C. B. King, K. E. Loesser, and S. Newton. 1997. Pectoral spine locking and sound production in the channel catfish Ictalurus punctatus. Copeia 1997:777-790.

Fine, M. L., and M. L. Lenhardt. 1983. Shallow-water propagation of the toadfish mating call. Comparative Biochemistry and Physiology A 76(2):225-231.

Fine, M. L., H. Lin, B. B. Nguyen, R. A. Rountree, T. M. Cameron, and E. Parmentier. 2007. Functional morphology of the sonic apparatus in the fawn cusk-eel Lepophidium profundorum. Journal of Morphology 268:953-966.

Fine, M. L., K. L. Malloy, C. B. King, S. L. Mitchell, and T. M. Cameron. 2001. Movement and sound generation by the toadfish swimbladder. Journal of Comparative Physiology 187:371-379.

Fine, M. L., and K. R. Pennypacker. 1986. Hormonal basis for sexual dimorphism of the sound-producing apparatus of the oyster toadfish. Experimental Neurology 92(2):289298.

Fine, M. L., and R. F. Thorson. 2008. Use of passive acoustics for assessing behavioral interactions in individual toadfish. Transactions of the American Fisheries Society 137:627-637.

Fine, M. L., H. E. Winn, L. Joest, and P. J. Perkins. 1977a. Temporal aspects of calling behavior in the oyster toadfish, Opsanus tau. U.S. National Marine Fisheries Service Fishery Bulletin 75:871-874.

Fine, M. L., H. E. Winn, and B. Olla. 1977b. Communication in fishes. Pages 472-518 in T. Sebok, editor. How animals communicate. Indiana University Press, Bloomington.

Finstad, J. L., and J. T. Nordeide. 2004. Acoustic repertoire of spawning cod, Gadus morhua. Environmental Biology of Fishes 70:427-433.

Fish, J. F., and W. C. Cummings. 1972. A 50-dB increase in sustained ambient noise from fish (Cynoscion xanthulus). Journal of the Acoustical Society of America 52:12661270 .

Fish, M. P., A. S. Kelsey, Jr., and W. H. Mowbray. 1952. Studies on the production of underwater sound by North Atlantic coastal fishes. Journal of Marine Research 11:180-193.

Fish, M. P., and W. H. Mowbray. 1970. Sounds of Western North Atlantic fishes. Johns Hopkins Press, Baltimore, Maryland.

Gannon, D. P. 2008. Passive acoustic techniques in fisheries 
science: a review and prospectus. Transactions of the American Fisheries Society 137:638-656.

Gerald, J. W. 1971. Sound production during courtship in six species of sunfish (Centrarchidae). Evolution 25(1):7587.

Gilmore, R. G., Jr. 2003. Sound production and communication in the spotted seatrout. Pages 177-195 in S. A. Bortone, editor. Biology of the spotted seatrout. CRC Press, Boca Raton, Florida.

Gray, G. A., and H. E. Winn. 1961. Reproductive ecology and sound production of the toadfish, Opsanus tau. Ecology 42:274-282.

Hawkins, A. D. 1986. Underwater sound and fish behaviour. Pages 114-151 in T. J. Pitcher, editor. The behaviour of teleost fishes. Groom Hellm, London.

Hawkins, A. D., and M. C. P. Amorim. 2000. Spawning sounds of the male haddock, Melanogrammus aeglefinus. Environmental Biology of Fishes 59:29-41.

Hawkins, A. D., L. Casaretto, M. Picciulin, and K. Olsen. 2002. Locating spawning haddock by means of sound. Bioacoustics 12:284-286.

Hawkins, A. D., C. J. Chapman, and D. J. Symonds. 1967. Spawning of haddock in captivity. Nature (London) 215:923-925.

Hawkins, A. D., and K. J. Rasmussen. 1978. The calls of gadoid fish. Journal of the Marine Biological Association of the United Kingdom 58:891-911.

Hill, G. L., M. L. Fine, and J. A. Musick. 1987. Ontogeny of the sexually dimorphic sonic muscles in three sciaenid fishes. Copeia 1987:708-713.

Holt, S. A. 2008. Distribution of red drum spawning sites identified by towed hydrophone array. Transactions of the American Fisheries Society 137:551-561.

Horne, J. K. 2000. Acoustic approaches to remote species identification: a review. Fisheries Oceanography 9:356371.

Ibara, R. M., L. T. Penny, A. W. Ebeling, G. Van Dykhuizen, and G. Cailliet. 1983. The mating call of the plainfin midshipman fish, Porichthys notatus. Pages 205-212 in D. L. G. Noakes, D. G. Lindquist, G. S. Helfman, and J. A. Ward, editors. Predators and prey in fishes. W. Junk Publishers, The Hague, The Netherlands.

Johnson, D. R., and N. A. Funicelli. 1991. Spawning of the red drum in Mosquito Lagoon, east-central Florida. Estuaries 14:74-79.

Johnston, C. E., and C. T. Phillips. 2003. Sound production in sturgeon Scaphirhynchus albus and S. platorynchus (Acipenseridae). Environmental Biology of Fishes 68:59-64.

Johnston, C. E., and S. P. Vives. 2003. Sound production in Codoma ornata (Girard) (Cyprinidae). Environmental Biology of Fishes 68:81-85.

Kaatz, I. 2002. Multiple sound-producing mechanisms in teleost fishes and hypothesis regarding their behavioral significance. Bioacoustics 12:230-233.

Lobel, P. 1992. Sounds produced by spawning fishes. Environmental Biology of Fishes 33:351-358.

Lobel, P. S. 2001. Fish bioacoustics and behavior: passive acoustic detection and the application of a closed-circuit rebreather for field study. Marine Technology Journal 35:2-19.

Lobel, P. S. 2002. Diversity of fish spawning sounds and the application of passive acoustic monitoring. Bioacoustics 12:286-289.

Lobel, P. S., and D. A. Mann. 1995. Spawning sounds of damselfish, Dascyllus albisella (Pomacentridae), and relationship to male size. Bioacoustics 6(2):187-198.

Locascio, J. V., and D. A. Mann. 2008. Diel periodicity of fish sound production in Charlotte Harbor, Florida. Transactions of the American Fisheries Society 137:606-615.

Lowerre-Barbieri, S. K., L. R. Barbieri, J. R. Flanders, A. G. Woodward, C. F. Cotton, and M. K. Knowlton. 2008. Using passive acoustics to determine red drum spawning in Georgia waters. Transactions of the American Fisheries Society 137:562-575.

Luczkovich, J. J., R. C. Pullinger, S. E. Johnson, and M. W. Sprague. 2008. Identifying the critical spawning habitats of sciaenids using passive acoustics. Transactions of the American Fisheries Society 137:576-605.

Luczkovich, J. J., M. W. Sprague, S. E. Johnson, and R. C. Pullinger. 1999. Delimiting spawning areas of weakfish, Cynoscion regalis (Family Sciaenidae) in Pamlico Sound, North Carolina using passive hydroacoustic surveys. Bioacoustics 10:143-160.

Lugli, M., H. Y. Yan, and M. L. Fine. 2003. Acoustic communication in two freshwater gobies: the relationship between ambient noise, hearing thresholds, and sound spectrum. Journal of Comparative Physiology A 189:309-320.

Mann, D. A., and P. S. Lobel. 1995a. Passive acoustic detection of fish sound production associated with courtship and spawning. Bulletin of Marine Science 57:705-706.

Mann, D. A., and P. S. Lobel. 1995b. Passive acoustic detection of sounds produced by the damselfish, Dascyllus albisella (Pomacentridae). Bioacoustics 6:199-213.

Mann, D. A., and P. S. Lobel. 1997. Propagation of damselfish (Pomacentridae) courtship sounds. Journal of the Acoustical Society of America 101:3783-3791.

Mann, D. A., and P. S. Lobel. 1998. Acoustic behavior of the damselfish Dascyllus albisella: behavioral and geographic variation. Environmental Biology of Fishes 51:421428.

McCauley, R. D., and D. H. Cato. 2000. Patterns of fish calling in a nearshore environment in the Great Barrier Reef. Philosophical Transactions of the Royal Society of London B 355:1289-1293.

Mok, H. K., and R. G. Gilmore. 1983. Analysis of sound production in estuarine aggregations of Pogonias cromis, Bairdiella chrysoura, and Cynoscion nebulosus (Sciaenidae). Bulletin of the Institute of Zoology, Academia Sinica 22:157-186.

Mueller, F. 1867. Letter to Charles Darwin, 17 July 1867. Darwin Correspondence Project Archives, Cambridge University, UK. Available: http://www.lib.cam.ac.uk/ Departments/Darwin/.

Myrberg, A. A. 1980. Fish bio-acoustics: its relevance to the 'not so silent world.' Environmental Biology of Fishes 5:297-304.

Myrberg, A. A. 1981. Sound communication and interception in fishes. Pages 395-425 in W. N. Tavolga, A. N. Popper, and R. R. Fay, editors. Hearing and sound communication in fishes. Springer Verlag, New York. 
Myrberg, A. A., S. J. Ha, and M. J. Shamblott. 1993. The sounds of bicolor damselfish (Pomacentrus partitus): predictors of body size and a spectral basis for individual recognition and assessment. Journal of the Acoustical Society of America 94:3067-3070.

Myrberg, A. A., Jr., M. Mohler, and J. D. Catala. 1986. Sound production by males of a coral reef fish (Pomacentrus partitus): its significance to females. Animal Behavior 34:913-923.

Neproshin, Y. A. 1972. Some physical characteristics of sound in Pacific salmon. Zoologicheskii Zhurnal 51:1025-1030.

NOAA (National Oceanic and Atmospheric Administration). 2007. The digital ocean: our oceans on a microchip. NOAA Sea Grant College Program, Silver Spring, Maryland. Available: http://www.seagrant.noaa.gov/ themesnpa/pdf/digitaloceans_main.pdf.

Nordeide, J. T., and I. Folstad. 2000. Is cod lekking or a promiscuous group spawner? Fish and Fisheries 1:90-93.

Perez, A. A., R. Wahrlich, P. R. Pezzuto, P. R. Schwingel, F. R. A. Lopes, and M. Rodrigues-Ribeiro. 2003. Deep-sea fishery off southern Brazil: recent trends of the Brazilian fishing industry. Journal of Northwest Atlantic Fishery Science 31:1-18.

Perkins, P. J. 2001. Drumming and chattering sounds recorded underwater in Rhode Island. Northeastern Naturalist 8(3):359-370.

Rome, L. C., D. A. Syme, S. Hollingworth, S. L. Lindstedt, and S. M. Baylor. 1996. The whistle and the rattle: the design of sound producing muscles. Proceedings of the National Academy of Sciences USA 93:8095-8100.

Roumillat, W. A., and M. C. Brouwer. 2004. Reproductive dynamics of female spotted seatrout (Cynoscion nebulosus) in South Carolina. U.S. National Marine Fisheries Service Fisheries Bulletin 102:473-487.

Rountree, R. A., R. G. Gilmore, C. A. Goudey, A. D. Hawkins, J. Luczkovich, and D. Mann. 2006. Listening to fish: applications of passive acoustics to fisheries science. Fisheries 31:433-446.

Rountree, R. A., P. J. Perkins, R. D. Kenney, and K. R. Hinga. 2002. Sounds of western North Atlantic fishes: data rescue. Bioacoustics 12(2/3):242-244.

Rowe, S., and J. A. Hutchings. 2004. The function of sound production by Atlantic cod as inferred from patterns of variation in drumming muscle mass. Canadian Journal of Zoology 82:1391-1398.

Rowe, S., and J. A. Hutchings. 2006. Sound production by Atlantic cod during spawning. Transactions of the American Fisheries Society 135:529-538.

Sadovy, Y., and W. L. Chung. 2003. Near extinction of a highly fecund fish: the one that nearly got away. Fish and Fisheries 4:86-99.

Saucier, M. H., and D. M. Baltz. 1993. Spawning site selection by spotted seatrout, Cynoscion nebulosus, and black drum, Pogonias cromis, in Louisiana. Environmental Biology of Fishes 36:257-272.

Saucier, M. H., D. M. Baltz, and W. A. Roumillat. 1992. Hydrophone identification of spawning sites of spotted seatrout Cynoscion nebulosus (Osteichthyes: Sciaenidae) near Charleston, South Carolina. Northeast Gulf Science 12:141-145.

Sprague, M. W., and J. J. Luczkovich. 2004. Measurement of an individual silver perch Bairdiella chrysoura sound pressure level in a field recording. Journal of the Acoustical Society of America 116:3186-3191.

Tavolga, W. 1958. Underwater sounds produced by the males of the blenniid fish Chasmodes bosquianus. Ecology 39:759-760.

Tavolga, W. N. 1960. Sound production and underwater communication in fishes. Pages 93-136 in W. E. Lanyon and W. N. Tavolga, editors. Animal sounds and communication. American Institute of Biological Sciences, Washington, D.C.

Tavolga, W. N., editor. 1964. Marine bio-acoustics. Pergamon Press, New York.

Tavolga, W. N., editor. 1967. Marine bio-acoustics, volume 2. Pergamon Press, New York.

Thompson, D. D.'A., (translator). 1910. Aristotle's Historia Animalism, IV, 9. Clarendon Press, Oxford, UK.

Thorson, R. F., and M. L. Fine. 2002. Crepuscular changes in emission rate and parameters of the boatwhistle advertisement call of the gulf toadfish, Opsanus beta. Environmental Biology of Fishes 63:321-331.

Tower, R. W. 1908. The production of sound in the drum fishes, the sea robin, and the toadfish. Annals of the New York Academy of Science 18:149-180.

Van Parijs, S., and B. Southall. 2007. Report of the 2006 NOAA National Passive Acoustics Workshop: developing a strategic program plan for NOAA's Passive Acoustics Ocean Observing System (PAOOS). Woods Hole, Massachusetts, 11-13 April 2006. National Oceanic and Atmospheric Administration, National Marine Fisheries Service. Available: http://www.nefsc. noaa.gov/nefsc/publications/tm/tmspo76.pdf.

Wahlberg, M., and H. Westerberg. 2002. Sounds produced by herring (Clupea harengus) bubble release. Aquatic Living Resources 16(2003):271-275.

Winn, H. E. 1964. The biological significance of fish sounds. Pages 213-231 in W. N. Tavolga, editor. Marine bioacoustics. Pergamon Press, New York.

Winn, H. E. 1967. Vocal facilitation and the biological significance of toadfish sounds. Pages 213-231 in W. N. Tavolga, editor. Marine bio-acoustics, volume 2. Pergamon Press, New York.

Winn, H. E., J. A. Marshall, and B. Hazlett. 1964. Behavior, diel activities, and stimuli that elicit sound production and reactions to sounds in the longspine squirrelfish. Copeia 1964:413-425. 